Murmurations:

Journal of

Transformative

Systemic

Practice

\title{
The systemic crisis of climate change: clinical and political reflections (2013)
}

and

\section{The EcoSystemic Return: clinical and political implications (2021)}

Volume 4

Issue 1

Philip Kearney

Winter 2021

Keywords:

systemic crisis,

EcoSystemic,

climate change,

ecology, extinction,

survival

Citation Link

In this special issue on the EcoSystemic Return, we have the honour of our Revival Paper being the 2013 paper by esteemed systemic ecology activist from Ireland, Philip Kearney. This paper is a reminder that the systemic community did not heed warnings about ecology issued by Gregory Bateson in the 1960s and 70s. In 2013, Phil Kearney reminded us again.

The original paper is followed by a fresh piece of writing for this special issue. Philip Kearney reignites his passion and anger, his critical analysis and call to action for this protracted phase of climate change complacency.

Sincere thanks and appreciation to Jim Sheehan and colleagues of Feedback: Journal of the Family Therapy Association of Ireland for permission to re-print the 2103 article which had the vision to provide a platform for this important work.

Citation for the original paper:

Kearney, P. (2013). The systemic crisis of climate change: clinical and political reflections. Feedback: Journal of the Family Therapy Association of Ireland, 1, 42-50. 


\title{
The systemic crisis of climate change: clinical and political reflections
}

\author{
Philip Kearney
}

\begin{abstract}
The ecological threats posed by climate change constitute the outstanding social, political and moral challenge of the 21st century. It is no longer in doubt that we are changing our world in significant ways and the consequences will be far-reaching, calling our very survival as a species into question. What role, if any, has systemic psychotherapy in responding to such a scenario? In an attempt to answer this question this paper gives an overview of the scale of the challenge faced by humanity and drawing on some foundational thinkers in the systemic tradition, argues for those with a systemic perspective to show leadership in formulating a radical response at both clinical and societal levels.
\end{abstract}

\section{The crisis}

The evidence of climate science suggests that within a generation the world will have been changed almost beyond recognition. The rapid melting of Arctic ice in recent years is but one very dramatic index of the escalating pace of change that is occurring at a planetary level. This has happened at a much faster rate than predicted by the collective wisdom of the world's climate scientists in the Intergovernmental Panel on Climate Change (IPCC) (12). The oceans are absorbing the steadily increasing temperature but they cannot do so indefinitely. The incidence of extreme weather events continues to escalate and the consequences will be increasing social disruption, economic collapse, significant loss of life, species extinction and mass migration.

The ecological crisis we are facing is unprecedented. It is overwhelming and deeply alarming. It is about discontinuous, irreversible, planetary change. The understandable reflex is to ignore, challenge, deny or dismiss it. A recent report of the International Energy Agency says that if we have five more years of escalating carbon emissions we will bypass the possibility of staying within the threshold of a $2^{\circ} \mathrm{C}$ increase in average global temperature which is regarded as essential to maintain the ecosystems on which we depend (2).

All previous threats - plague, famine, war (including nuclear) - allowed for the possibility of continuity of the species even if there was massive attrition. This threat goes much further. James Lovelock, a British scientist, has predicted a huge reduction of the human population before the end of this century perhaps to one billion from the current seven billion (3). Those surviving will be in a largely 'unlivable world' - a phrase I have taken from Mary Robinson, former president of Ireland (and currently UN Special Envoy on Climate). Lovelock is best known for his theory of the earth as a selfregulating, living system. This hypothesis, which he named Gaia after the Greek goddess, has now become one of the foundations of much contemporary climate science.

My intent is not to be alarmist for its own sake or to spread panic. But such is the scale of the potential catastrophe that threatens many of our species and others that there is a moral imperative to declare 
the truth and not to soften the blow. Panic may be regarded as an appropriate psychological response to the factual situation.

At the same time I have a deep confidence and belief in the creativeness and resilience of humankind. The capacities to respond to the emerging ecological threats are there - both in terms of technology (although that will not be a panacea) but also in terms of learning to live with less and treading more lightly on the planet and its ecosystems. However the scale of the adjustment required in lifestyles and consumption has previously occurred only in wartime or in response to a major calamity. Is this threat equivalent to wartime? Not in the public mind but in other respects, perhaps. The onslaught on our essential ecosystems is just as fierce as if we had deliberately decided on ecocide. The rates of deforestation, soil erosion, resource depletion, water wastage, glacial retreat, fossil fuel extraction and carbon emissions are continuing to escalate in spite of the accumulated scientific knowledge telling us that we are severely compromising the prospects for future generations.

This paper is addressed primarily to my colleague systemic psychotherapists. This modality of therapy is my professional home and I am pleased to have played some part in its development. We share many values with the other psychotherapies and health disciplines - i.e. seeking the reduction of human suffering, physical and mental, the enhancement of human well-being and the maximising of the potential of all, adults and children. Many of us chose to enter our professions precisely because of these principles and aspirations. A commitment to increasing health, happiness and well-being or reducing their opposites motivated us to undertake extensive and demanding training.

How do we now equate those initial impulses with the news that all that we take for granted is under threat, that we are part of an extinction process which is well advanced and the time available to redress the harm is reducing rapidly (4). At what level of risk do we as professionals have to act collectively or individually? What do our codes of ethics have to say about this? Fundamentally as therapists we are engaged in professions and practices that prioritise and value human well-being and work to restore it where it is in distress or gone awry. Much has now gone awry in the ecosystems that sustain us:

- The oceans are overfished to dangerous levels where mass extinctions are predicted (5);

- The rate of global carbon emissions continues to rise annually;

- There is little prospect of binding international agreement to halt this escalation;

- The world's poor seek the lifestyles and commodities we, the wealthy, take for granted;

- The rate of extreme weather events with devastating impacts has increased dramatically.

The scale of denial of these facts at all levels is staggering, the official and political inertia frightening. The belief of some who have studied the science and have the training to read it is that collapse of all the principal systems which sustain us - economic, energy, food, transport and IT is an inevitability (6, $7,8,9,16)$. The only uncertainty is when.

Given a potential risk of this scale what does this oblige us to do - either as citizens or as health care professionals? If, in our practice, we encountered an assessment of risk where extensive harm appeared inevitable what would we do? There would be an obligation to report and to act. I am now making such a report. I am obliged to report to you that the threat of massive loss of life and suffering 
has been identified and action is required. In this scenario we are both perpetrators and victims - to varying degrees.

If not immediately a state of emergency, it is at the threshold of one. Our children and theirs are at profound risk of serious injury and death and their life chances will be hugely circumscribed by the actions we are now taking and perhaps, more significantly, by the ones we fail to take.

\section{The legacy of Bateson}

The systemic perspective is central to understanding the dynamics of climate and the delicate balances that have been destabilised by human activity - predominantly wealthy Western humans.

Gregory Bateson, ecologist and intellectual guru of systemic therapy, spoke of the circularity in all living systems and the critical balance between variables in an ecosystem $(10,11)$. He highlighted that there are optimal values of most variables in a given ecosystem. If those values are exceeded the system's survival is in jeopardy. Oxygen is a very good example: if the proportion of oxygen in the air we breathe increases by quite a small amount we are poisoned. $\mathrm{CO}^{2}$ is another. Human population is another. We are disturbing the mix of variables - chemical and biological - that have sustained life on the planet in its present forms for millions of years and have allowed the development of civilisation over the past ten millennia. We are doing this both because there are so many of us but primarily because some of us are consuming resources and generating carbon emissions at levels never before experienced.

The collective and conservative scientific consensus as expressed in the Intergovernmental Panel on Climate Change reports (12) is that the increase in global temperature is due to human intervention anthropogenic global warming. Much of this is irreversible and of delayed effect so we and our children will live in an increasingly warmer world whatever we do.

There are now many texts $(3,6-9,16)$ detailing the consequences of various possible levels of warming - of increasing levels of disruption to lifestyles, habitats and food production resulting in significant population migration as well an escalating rate of species loss. At the upper levels of $3^{\circ}-6^{\circ} \mathrm{C}$ of average warming the scenarios are catastrophic for many parts of the world and call into question the continued functioning of civilised society as we know it. There is widespread agreement that we must keep average warming below a threshold of $2^{\circ} \mathrm{C}$ to avoid such consequences.

Bateson admonished us forty years ago that 'the unit of survival is organism plus environment' ... 'we are learning by bitter experience that the organism which destroys its environment destroys itself.' $(10$, p. 483). He also spoke eloquently and frequently of the 'pattern which connects' by which he meant the endless tapestry of interweaving ecosystems from the micro to the macro of the planet itself that collectively constitute and sustain life. The pattern which connects living systems is currently being torn apart - perhaps irreversibly. We are on the cusp of an environmental catastrophe of huge proportions with major implications for all life forms on the planet.

Bateson described 'chopping up the ecology' as the most serious epistemological error. Most of our professional distinctions and political differences are predicated on chopping up the ecology and then shoring up the defences around our piece of territory. The sovereignty of the nation state has precedence over the integrity of the biosphere. Many of Bateson's ideas are echoed in the work of 
Lovelock who believes we have passed the point where the positive feedback loops can be prevented. They are underway. We are heading for massive changes in the way that Gaia balances her ecosystems and our species will not be a beneficiary. (3).

\section{The scale of the threat}

To be more precise we are already well beyond the carrying capacity of the planet. We have been floating on a sea of oil that is essentially concentrated solar energy distilled over millions of years. We are going to consume most of it in two centuries or less. Based on this oil we have had a huge explosion of food production that has enabled a similar population explosion. Oil underpins every aspect of our contemporary technological, industrial and commercial world. Without that lubrication we grind to a halt. It is a species-level dependency with all the worst features of the addictions we observe and treat in our clinical practice.

Because of our knowledge of systems and particularly of feedback processes the systems therapists ought to understand better than most the runaway escalations that are pushing us towards a tipping point. We ought to be well placed to discern, advise, interpret and warn but - like others - we are distracted by the pressing concerns of practice and teaching, academic demands and professional issues as well as significant financial constraints. As individuals or citizens the scale of the challenge may well overwhelm us. Its full import is an emotional and psychological tsunami.

\section{Our systemic legacy}

It is good to remember that the pioneering phase of our field 50 years ago constituted a revolution in thinking and practice which expanded the prevailing understanding of human interactional behaviour and emotional functioning. It promised new ways of conceptualising multi-person communications and the relational domain. It was a quantum leap.

Using Batesonian theory many family therapists such as the Milan Associates went a long way towards breaking the mould of the focus on the single patient and opened up the window to a greater sense of the web of interconnections within which symptoms and problems arise and are sustained (13). It was a fertile period for our modality.

However there was limited follow through on the (eco)logical implications to expand this frame to include the wider social and political context in which the families were embedded. Milan took the Batesonian message but restricted its application to micro human systems only - as if they could be addressed apart from their contexts. Bateson would not have approved.

The systemic therapy revolution of the $60 \mathrm{~s}, 70 \mathrm{~s}$ and 80 s can be seen as the psychological sciences' attempt to understand the wider human systems of which we are a part and to devise means of working therapeutically with those relationship networks. Our pioneers realised that we are born of relationship into networks and contexts of meaning which sustain or harm us and we them. However, unlike Bateson, they did not include the larger ecological context that is the cradle, the source of nutrients and energy and completes the systemic whole. 
The effort to widen the lens continued in various forms but has largely succumbed to the constraints of the established order. We have not followed through with the logic of an ecosystemic epistemology. This would require us to widen our lens to include the other living systems with which we share the planet and that of the planet itself. That would have the consequence of us having to question our interaction with and impact on those ecosystems. Second-order change or collusive blindness would then be the critical options.

By revisiting our systemic origins we can be pathfinders for our professional peers and students and perhaps for others. We can reclaim the innovatory, paradigm-shifting inspiration of the early founders of our field. However to do this we must go beyond psychology, politics, and economics as presently construed. They are each dedicated to fragmentary territorial views, invested in individualism, polarisation, or worship of the market respectively.

The situation is dire - perhaps not as dire as Lovelock proclaimed - but certainly urgent. To repeat, it is an emergency. We are in a state of collective denial about the scale of the challenges that confront us which are either a) to turn things around or b) to face the consequences if we can't or won't.

\section{Nagy and relational ethics}

Ivan Boszormenyi-Nagy - my former professor in Philadelphia - was a major influence in my formation as a family therapist. He was the founder of contextual therapy and he, more than any of the pioneers in the field, sought to incorporate an ethical dimension into his model of practice. He spoke of relational ethics and of balances of entitlement and indebtedness between the generations. He saw the lack of reciprocity and trustworthiness in primary relationships as a principal source of pathology (14). Nagy's call for reciprocal fairness and accountability between and across the generations as foundational for healthy human functioning seems incontestable. He gave those intergenerational dynamics a greater ethical dimension and emphasis than any of the other leading figures in our field.

His model has not had widespread popularity but perhaps it deserves closer attention now as we consider the world we are bequeathing to our children. We persist with consumption predicated on an infinite supply of raw materials while knowing that we live on a finite planet where the upper limits of many essentials - water, soil and clean air - are being reached. The myth that each succeeding generation can do better than the last no longer applies. What will be the consequences for intergenerational trust and justice when our children discover that we have depleted these critical resources and compromised their futures? Should we withhold this information from them or try to share it? What will they believe and think of us when they realise they are growing into an unlivable world? Ban Ki-moon, UN General Secretary, has recently declared:

"We are the last generation that can take steps to avoid the worst impacts of climate change".

Nagy's wife Catherine DuCommun-Nagy has continued to develop contextual therapy and says 'posterity is the main client of the contextual therapist.' That is an interesting thought. What if we conducted our therapy with posterity in the room as part of the system? This is a form of child protection that upon which we could usefully reflect. What if our practice included the entitlement of the next and future generations - what then, clinically and politically? 


\section{Conclusions}

The formulation I am proposing is to add the relational ethics of Nagy to the systemic rigour of Bateson at all levels of our practice and positioning as clinicians and as citizens. Nagy's perspective would require us always to take the emerging generations into account. This is a key principle of sustainable development as defined in the report of the Brundtland Commission in 1987:

"Development that meets the needs of the present without compromising the ability of future generations to meet their own needs". (15)

Such an awareness of the claims of posterity would go some way to counter the delusion that we can carry on as we are and the denial of what we are facing.

How would our practice and our politics change if we took Bateson seriously and saw the organism plus environment as the indivisible unit of evolution, of life and of survival? Then we would not draw a boundary around the individual, the couple or the family in our clinical enquiries. We would not permit our politics to chop up the ecology. Such an expansion of our consciousness of the network of relationships in which we reside and on which we depend may be crucial not just to the future of our discipline but to the destiny of our species.

\section{Acknowledgements}

Grateful thanks to Imelda McCarthy, Ed McHale, Jim Sheehan, Aine O'Reilly and Christina Soulios for their helpful comments on earlier drafts.

This is a revised version of a paper presented at conferences in Krakow (2009), Cardiff and Paris (2010), Berlin (2011) and Dublin (2012).

\section{References}

(1) Strasbourg declaration

https://www.europsyche.org/about-eap/documents-activities/strasbourg-declaration-on-psychotherapy/

(2) International Energy Agency report

http://www.iea.org/

(3) Lovelock, James

The Revenge of Gaia: Earth's Climate Crisis \& The Fate of Humanity, 2006, Basic Books.

(4) TEEB - The Economics of Ecosystems and Biodiversity

(5) State of the Oceans report

www.stateoftheocean.org/

(6) Flannery, Tim

The Weather Makers: How Man Is Changing the Climate and What It Means for Life on Earth, 2005, Text Publishing Company, Melbourne. 
(7) Monbiot, George

Heat: How to stop the planet burning. 2006, Allen Lane, Penguin Press.

(8) Lynas, Mark

Six Degrees: Our Future on a Hotter Planet, 2008, National Geographic.

(9) Hansen, James

Storms of My Grandchildren: The Truth About the Coming Climate Catastrophe and Our Last Chance to Save Humanity, 2009, Bloomsbury.

(10) Bateson, Gregory

Steps to an Ecology of Mind, 1972.

(11) Bateson, Gregory

Mind and Nature, 1979.

(12) Intergovernmental Panel on Climate Change

http://www.ipcc.ch/publications_and_data/ar4/syr/en/contents.html

(13) Selvini Palazzoli, Mara et al

Paradox and Counterparadox: A New Model in the Therapy of the Family in Schizophrenic Transaction, 1990, Jason Aronson.

(14) Boszormenyi-Nagy, Ivan and Spark, Geraldine

Invisible Loyalties: Reciprocity in Intergenerational Family therapy, 1973,

Harper and Row.

(15) World Commission on Environment and Development's

(the Brundtland Commission) report, Our Common Future, 1987, Oxford University Press.

(16) Hamilton, Clive

Requiem for a Species: Why We Resist the Truth about Climate Change, 2010, Earthscan.

\section{Citation for the original paper:}

Kearney, P. (2013). The systemic crisis of climate change: clinical and political reflections. Feedback: Journal of the Family Therapy Association of Ireland, 1, 42-50. 


\section{The EcoSystemic Return: clinical and political implications}

\section{Philip Kearney}

I am no longer a clinical practitioner, having taken a sabbatical from the clinic and directing training in the mid-noughties after thirty years and discovered I did not wish to re-enter. Since then I have focused my energies as a climate activist and organiser.

My 2013 paper (Kearney, 2013) was an attempt to convey the mounting concerns about the climate crisis to my former professional context. I spoke at various conferences and distilled my ideas into the paper. It is republished here for which I am grateful since it disappeared almost without trace on its first outing.

I support the intent of the Ecosystemic Return initiative - to reclaim our ecological roots - and I want to explore what the full import might be should we manage to do this.

Did we ever embrace the ecosystemic epistemology articulated by Bateson and briefly developed by Auerswald and Keeney? (Auerswald, 1968, 1971; Keeney, 1979, Keeney \& Sprenkle, 1982). I suggest not. For a whole host of reasons. We were understandably preoccupied with defining the features and location of our new modality over against what had gone before. We used elements of the Batesonian paradigm and other sources to do so but we were obliged to find a place within the existing mental health infrastructure and industry with all the constraints that that implies. As Gail Simon says so vividly about the current dilemma for systemic therapists in mainstream services, "To be employed in a medical model renders us either delinquent or magician." (Simon, 2021, p. 11).

These preoccupations diluted the rigour and imagination of Bateson's vision and his ideas were adopted only in fragments and partial arcs. Hugh Palmer captures this very well in his paper in this issue of Murmurations (Palmer, 2021). He and I share a common homage to the master.

I was given the privilege and opportunity to have sight of some of my fellow writers' papers (Palmer 2021; McCarthy 2021; Simon 2021) as I prepared my own. That access influenced my thinking and helped me to reorient to the current concerns of systemic therapy practitioners and teachers. I ask my three colleagues' forgiveness and indulgence as I have engaged in some critique of their papers to bolster my arguments. I invite them to do likewise with my claims and positions.

Gail's paper is a visionary and potentially transformative account of the radical restructuring required to navigate a way through the multiple challenges and threats of the panmorphic crisis. It locates systemic therapy and training as potentially pivotal in that transformation but only if these practices widen their lens and accommodate a host of new perspectives, other voices and languages. All of the papers (including mine of 2013) acknowledge the scale of the multiple crises we face and all attempt in various ways to address it in the formulations and arguments.

The papers contribute enhanced visions of how our practice both as therapists, trainers and citizens might be transformed through a return to systemic rigour coupled with additional lenses of spirituality, inclusion and ecology. They are prologues to an as yet unwritten text that may more fully integrate the imminent demise of contemporary civilisation predicted by climate science and social and political inertia. 


\section{The planet as patient - does the Earth need therapy?}

The climate/biodiversity crisis is sui generis, a unique and unprecedented risk to most of the biosphere potentially ending human endeavour in all of its forms. It implies a conclusion of the world as we have come to know it.

It is not the death of the planet. This is vitally important to recognise as this ubiquitous mantra involves a massive displacement relocating our plight from anthropogenic ecocide to the idea that the planet as a whole is at some sort of risk. Myriad life forms and many civilisations have come and gone on Earth. We are simply part of the latest and very recent iteration. Our demise will pave the way for another configuration to emerge in a geological eyeblink of some millions of years.

The notion that we can or should "save the planet" is misplaced and avoids the reflexivity that would acknowledge our part in the mutually assured destruction that is underway. It is a serious distraction from the more urgent agenda of radical emissions reduction and reversal of biodiversity collapse.

Any planetary malaise is entirely of our making and those currently suffering and succumbing are the most vulnerable of our species and many other species besides. This process is very advanced and escalating. There are many excellent analyses of how it has come to pass, some referenced in my Systemic Crisis paper and many more since, especially the IPCC reports (IPCC, 2018, 2021). Very few of them fully factor in the inevitable consequences if we persist in our current economic and political practices.

The analyses in the various articles are articulate and visionary. While operating largely within existing categories of knowledge, science, language and practice, they seek to expand that envelope to incorporate transformative visions of justice, inclusion, indigenous knowledge and marginalised voices going beyond an anthropocentric fixation. All of these perspectives are vital to a transformed world order where the eco-apocalypse might be averted and ecosystemic balance restored.

In my view the shared missing elements are the prospect of apocalypse and the urgency implied by the short time remaining. To be fair, Gail says:

There is no linearity to this transition. It is not like any other change we can compare it to. It is an all-in-one explosion of Things That Must Be Acknowledged And Addressed Now.

(Simon, 2021, p. 8)

This is an unequivocal grasping of the nettle of the panmorphic crisis. It is then somewhat undone in my view by speaking of "sinking into a suspended state of systemic liminality" or hoping that stumbling blocks may trip us towards transformation. Do we have time for those luxuries? I don't think so.

Without an acknowledgement of our vulnerability and precarity, it appears to me that the scale of transformation required and proposed in these four papers has little prospect of achievement within the short window still available to us. With that acknowledgement, the liminal space between our current rampant disorder and a world that lives within planetary boundaries may be glimpsed.

The papers in this special EcoSystemic Return issue are more than honourable attempts to address this challenge. I am presumptuous enough to declare that we all fail. They all articulate valid and valuable contributions to the task at hand - revisioning our practice and discipline while holding in mind the range of contemporary existential threats, but they continue to do so within existing clinical, academic and political parameters. A quantum shift is required. And that implies disruption, I assert. 
Again, to be fair, there are hints of disruptive potential - Hugh speaks of trouble-making and Imelda calls our attention to the capacity of equanimity to exert a profound perturbation at all levels, personal, professional and political.

My case is that all of us avoid the full implications of a final meltdown as expressed by @GretaThunberg in her call that the house is on fire and we should treat a crisis as a crisis.

We remain within our existing categories of the clinical (although with dramatically expanded definitions), the academic (in terms of the conventions of referencing protocols, peer review and paying homage) and the legal (not straying into the inflammatory or the subversive - although that is where we may be headed).

The knot cannot be unravelled from within its own confines. It necessarily requires the kind of observer position proposed by many in our field building on Bateson's double description (Bateson 1979). My point is that the observer position must accommodate the full import of the current disastrous trajectory and its immediacy - the only question is whether it will be the climate crisis, biodiversity collapse, food riots, another more virulent pandemic or a cocktail of all of these that will trigger Armageddon.

What would we say and write if we fully absorbed the scale and closeness of civilisational collapse and the possibility that we may not make it?

I am keenly aware of the potential charge of being an alarmist catastrophist. I have to accept the label but wish to argue that it is in service of change and transformation, not an end in itself.

\section{A Fifth Province Diamond - the Ecosystemic Return}

In an effort to craft an addendum to my 2013 paper and address some of its limitations I have drawn on the methods and practice developed by Imelda McCarthy, Nollaig Byrne and myself over many years as a clinical research team (Kearney et al., 1989; Kearney, 2002; McCarthy, 2001; Byrne and McCarthy, 2007).

We devised a form of mapping to capture and express the key themes of the context, conversation and system in which we found ourselves. We used a diamond configuration to juxtapose (apparent) polarities in a two-dimensional frame. This then constructed or brought forth four quadrants of interaction and possibility that hopefully approximated the systemic complexity in which we found ourselves immersed. There are always a multitude of starting points and options and opposites. There is no right place to begin or route of travel. I offer a draft rough diamond below: 


\section{EcoSystemic Return}

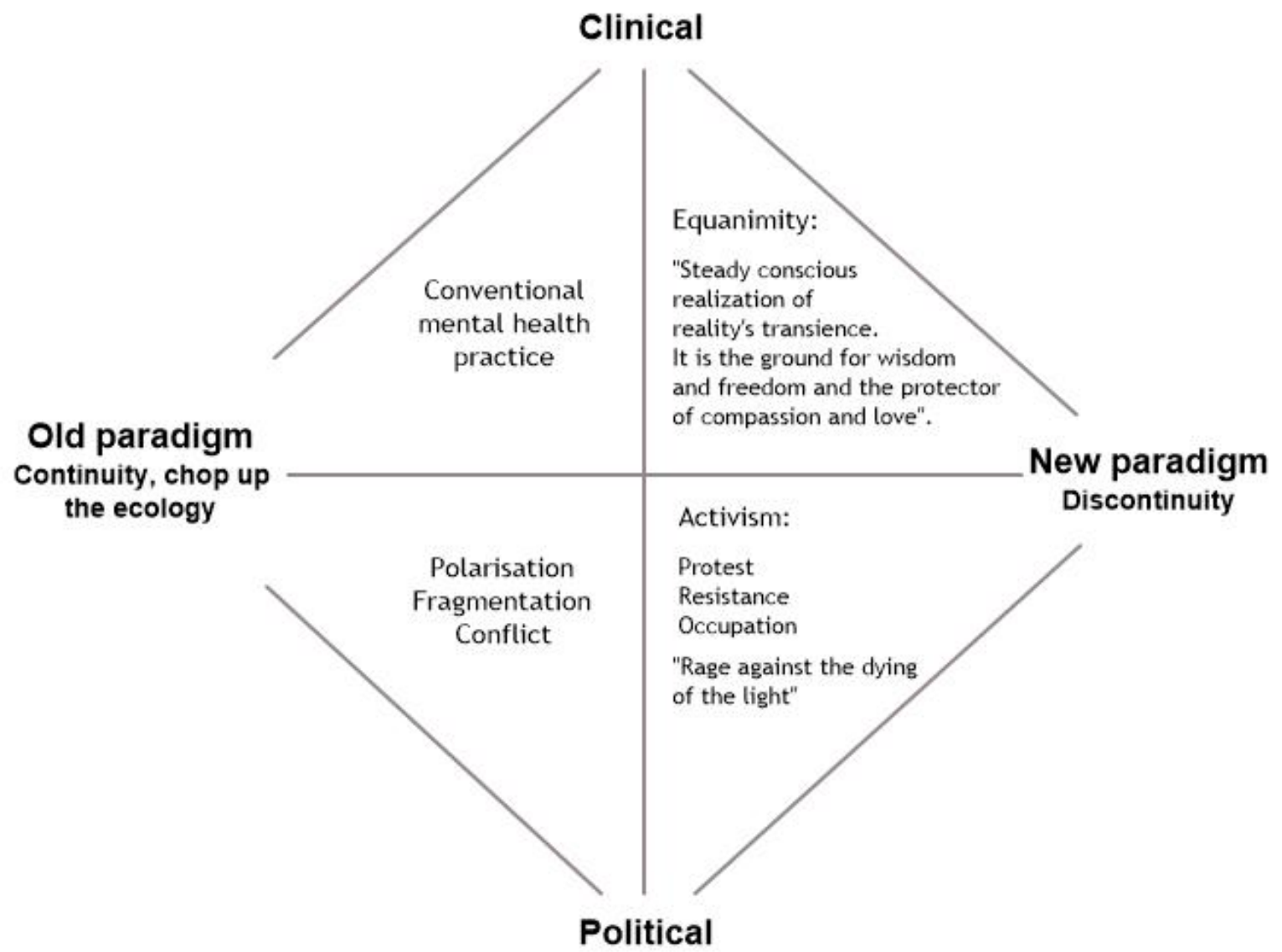

As a first set of polarities I opted for a crude and exaggerated distinction of old and new paradigm. This is very influenced by Bateson's work (thoroughly honoured in Hugh's paper) (Palmer, 2021) which offers a new paradigm of ecosystemic resilience that is not yet realised. His ecological vision and identification of mind and nature as a necessary unity have been validated by the passage of time. It has been reworked and enhanced but neither dismissed nor implemented. Many (most/all?) indigenous cultures lived in this way before the interventions and colonisations of our predecessors.

Most of the clinical (and political) literature remains embedded in the old paradigm of linear causality, expert discourses chopping up the ecology in the way that Bateson warned against. In spite of our best efforts to break out of that frame the constraints and inertia of commerce, culture and practice keep us enchained. Equally, the repetitive, counterproductive and divisive methods of contemporary politics keep us fragmented, polarised and in conflict of various kinds. The momentum of the existing paradigm of consumerist, extractivist entitlement is irresistible with us all colluding to varying degrees.

My contention is that only a full absorption of the imminence and existential significance of species extinction - including our own - can catalyse a new paradigm response of greater collaboration at the level of human interaction and a return of humanity to its prior status as a part of the natural world rather than its nemesis. The Greek terms certainly offer insight and leverage. Bateson redefined hubris as the "lack of systemic wisdom," (Bateson, 1972) the tragic blindness that occurs when any part of an ecological system ignores the fact that it is participating in a system larger than itself, one upon which its very existence is predicated. 
This is as precise a diagnosis of our predicament as I can find.

On my other axis in the diamond, I have placed "clinical" and "political". They may not appear as polarities. They are very personal options reflecting my own predilections. They are the defining categories of my adult life outside (and maybe inside?) the family. I mentioned them in the title of the 2013 paper, "The systemic crisis of climate change: clinical and political reflections".

This action now opens the four quadrants.

It is important to underscore that this is but one version. Had I drawn this diamond with my two Fifth Province colleagues, or anyone else, it would be different. It is of course much better to bring multiple minds to bear in prospecting for diamonds as a richer tapestry unfolds. This is not presented as a definitive map of anything, it is my projection and allows me some distance from the web in which I am ensnared. More hermeneutic than exegesis.

It allows me to see two pathways towards a new paradigm of practice - be it therapeutic, political or spiritual. There is the pathway of equanimity, a central concept in Imelda's paper (McCarthy, 2021), or that of activism, my preferred medium. They are not necessarily mutually exclusive, but quite distinctive.

If I had a third axis I would have added extinction and survival as the parameters. (In the Fifth Province work we struggled with but never fully managed to achieve 3-D diamonds.)

\section{The activist rant: the exigencies of ensuring survival}

This is a fight for the lives of our children. Most of us over fifty have had a good innings and will probably not see the worst ravages of climate chaos. But by continuing inaction, we consciously ensure that many of those now alive and all of those still to be born will endure an increasingly uninhabitable earth. (Chatham House, 2020; Wallace-Wells, 2019).

Therefore what follows becomes increasingly and unequivocally political. All of our existing categories of occupation and practice become secondary to the exigencies of ensuring survival. All choice to do otherwise is delusional and destructive.

Without doubt it is the overarching health risk of all human time (Lancet, 2021).

Those with particular skills in the area of human behaviour and psychology must deploy those resources to influence the radical shift required at all levels. The guilds of health workers must redefine their modus operandi to reflect the rapidly growing threat to the health and well-being of many millions in the short to medium term and to most of humanity in the longer-term - if there is a longer-term for humanity. I am aware that I am being strident and instructive, abandoning equanimity and balance with too much conscious purpose. Bateson would twirl in his grave.

Perhaps the activist quadrant is the epitome of the hubristic behaviour that Bateson condemned - one part of the system attempting to unilaterally influence or force a particular outcome? It is the antithesis of a recognition of the necessary unities and complementarities that make up the whole. However a paradigm of practice that fully embraces the complexities of indigenous knowledge in terms of our relationship to the land, nature and food production and a reduction in our extractivist and consumerist preoccupations would be an informed and holistic activism with greater survival potential. 


\section{Planet as patient}

As already stated above but perhaps worthy of rehearsing in the domain of therapists, it is crucial to cast aside the widespread displacement meme of "saving" or "healing" the planet. The planet is in no danger whatsoever and does not require saving or therapy. It is indifferent to our presence or absence and will continue to host other life forms long after we are gone. The myth of caring for/saving the planet distracts from and disguises the reality that it is us and our civilisational conceits that are at serious, escalating and short-term risk and that we are also the perpetrators of the threats. For "us/we" in this context please read the wealthy of the West and elsewhere. Every flight, every steak and every flick of a light switch, in fact every purchase, contributes to the demise of others and compromises our collective future. Only comprehensive rationing of almost everything backed by draconian regulation now has any prospect of turning things around. I am not blind to the potentially dangerous negative consequences of such prescriptions.

It is clear that conventional politics and multilateral action by the world's nation states is not up to the job. Incrementalism marginally delays meltdown and in many ways expedites it.

It appears that the rigorous intervention of governments and health authorities during the Covid-19 pandemic has been effective and may be the necessary template for the survival response. A radically different economics is being articulated by authors such as Kate Raworth (2017) and Jason Hickel (2021) promoting degrowth and operating within the constraints of key planetary boundaries (Rockström, 2009). This is, in effect, a new ethic of survival through a counterintuitive, "less is more" ethos, involving the deconstruction of consumerism and delegitimation of all fossil fuel use, extraction, advertising and subsidisation. Much will grind to a halt as it did in lockdown. But health outcomes will immediately start to improve.

Isn't that what we health professionals are supposed to be about?

The crucial difference is that there is no vaccine in the pipeline, no science or tech-based quick fix that will rescue us. Either there will be a radical reordering of values and a massive collective revolution in our lifestyles by a substantial section of our developed country populations or it will be lights out for most if not all. All tinkering and partial response is merely soothing ourselves and whistling past the graveyard. We are already so far beyond safe levels on a range of critical measures as to seriously question whether a realignment of the kind I describe is viable. The pandemic response of communities, some governments, many health and other key workers suggests that in the face of a clearly understood global threat, widespread and sustained behaviour change is achievable. It requires visionary and trustworthy leadership. However, the rebound to business as usual is already well underway in travel, online purchasing and everything else. It poses an enormous threat to ecosystem viability.

Consequently, I propose that the terms of reference of every committee and the vision and mission statements of every organisation (therapeutic and otherwise) be rewritten with survival in its most basic sense as the principal and primary objective. Everything then flows from that shift.

Almost all current climate action plans are incremental attempts to retune the engine while in flight keeping the same long-haul destination on the screen. This is the core delusion. There is only one destination possible if we sustain our current trajectory - civilisational meltdown through a series of cataclysms within a generation or two at most. The underpinnings of our current economic and political operating systems are predicated on extraction leading to extinction. 
Our present raison d'être is fundamentally flawed and must be disrupted. It is not a "reason to be" but a licence to extract and consume as if that is the purpose of life on earth. It is not just debased and destructive but also the antithesis of a formula for flourishing as a species within a network of ecosystems. This must be the cornerstone of revised educational programmes at all levels - including for all health professionals.

I have attempted above to provide a diagnosis of the most significant health issue facing humanity and to sketch an outline of the essential prerequisites for remediation. We, the systemic psychotherapists, are a small subset of the health industry. The initiative for a radical repositioning must start somewhere. For the Ecosystemic Return to have validity and authority, those systemic therapists who claim an ecosystemic perspective must be in the vanguard of transforming their operations at every level from practice, to organisational to educational and in terms of lobbying and campaigning. Anything else is merely tinkering, potentially collusive and self-deceptive.

For me the overarching threat of extinction is primary as both a political and spiritual motivator and I find myself wanting to draw the attention of the wider public to this as a catalyst for action. I fully accept that for many this is currently and will remain a bridge too far. No amount of haranguing will persuade those who cannot contemplate an unliveable world or imagine an end to the chain of generations stretching out before us. But not admitting the scientific evidence or deluding ourselves about techno-fixes or magic bullets contributes to the escalating slide towards extinction - within a relatively small time window.

Of course, in the face of the transience of all things, it is entirely valid to choose equanimity and to cultivate balance and harmony in our daily lives, work and interactions as a primary response to the panmorphic crisis. That also moves the world towards a new paradigm of enlightened awareness and wholism. It may indeed be the better route to go and we may have no option. If only we had the time and political processes that could respect and respond to the values and practice of equanimity.

Where does ecosystemic therapy and training fit in this diamond?

Unless it includes ecology, bodywork, meditation and equanimity it will be likely to remain trapped in the upper left-hand quadrant, I suggest. Probably many of you would add other additional courses and requirements to that list. It then becomes overloaded and blurs into training for life. But maybe that is fine, if it contributes to the continuation of the existing life forms on the planet.

To become preoccupied with survival in a benign, collaborative and activist modality strikes me as a good formula for creative disruption. It could only be enhanced by association with meditative practice informed by spiritual traditions and indigenous wisdom.

The EcoSystemic Return workshop in June included an invitation "to reclaim our relationship with subjugated Indigenous ecological wisdom and epistemologies to build a future based on both ecological and social justice". The rupture and dislocation we are seeking to heal is of such significance and pervasiveness that it requires shedding anthropocentrism, abandoning techno-optimism, listening to the music of nature and eschewing the myth of "progress". Otherwise we may lose everything.

\section{References}

Auerswald, Edgar. H. (1968). Interdisciplinary versus Ecological Approach. Family Process, 7(2), 202-215. https://doi.org/10.1111/j.1545-5300.1968.00202.x 
Auerswald, Edgar. H. (1971). Families, change, and the ecological perspective. Family Process, 10(3), $263-280$. https://doi.org/10.1111/j.1545-5300.1971.00263.x

Bateson, Gregory (1972). Steps to an Ecology of Mind, New York: Ballantine.

Bateson, Gregory (1979). Mind and Nature: A Necessary Unity. New York: E. P. Dutton.

Byrne, Nollaig O’Reilly \& McCarthy, Imelda C. (2007). The Dialectical Structure of Hope and Despair: A Fifth Province Approach in Flaskas, C., McCarthy, I. \& Sheehan J. (Eds) Hope and Despair in Family Therapy: Reflections on Adversity, Forgiveness and Reconciliation. London: Routledge.

Chatham House (2021). Climate change risk assessment 2021. Summary of research findings. https://www.chathamhouse.org/sites/default/files/2021-09/2021-09-14-climate-change-risk-assessmentsummary-quiggin-et-al_0.pdf

Hickel, Jason (2021). Less is More: How Degrowth Will Save the World. London: Penguin Random House.

IPCC (2018). Summary for Policymakers. In: Global warming of $1.5^{\circ} \mathrm{C}$. An IPCC Special Report on the impacts of global warming of $1.5^{\circ} \mathrm{C}$ above pre-industrial levels and related global greenhouse gas emission pathways, in the context of strengthening the global response to the threat of climate change, sustainable development, and efforts to eradicate poverty. https://www.ipcc.ch/report/sr15/summary-for-policymakers/

IPCC (2021). Climate Change 2021: The Physical Science Basis. Working Group I Contribution to the Sixth Assessment Report of the Intergovernmental Panel on Climate Change. Cambridge University Press. https://www.ipcc.ch/report/sixth-assessment-report-working-group-i/

Kearney, Philip; Byrne, Nollaig \& McCarthy, Imelda (1989). Just Metaphors: Marginal Illuminations in a Colonial Retreat, Family Therapy Case Studies, 4, 17 - 31.

Kearney, Philip (2002). A note on the Fifth Province Diamonds. Feedback: Journal of the Family Therapy Association of Ireland, 9(2), 11-14.

Kearney, Philip (2013). The systemic crisis of climate change: clinical and political reflections. Feedback: Journal of the Family Therapy Association of Ireland, 1, 42-50.

Keeney, Bradford (1979). Ecosystemic epistemology: an alternative paradigm for diagnosis. Family Process, 18(2), 117-29. https://doi.org/10.1111/j.1545-5300.1979.00117.x

Keeney, Bradford \& Sprenkle, Douglas (1982). Ecosystemic epistemology: critical implications for the aesthetics and pragmatics of family therapy. Family Process, 21(1), 1-19. https://doi.org/10.1037/10112-041

McCarthy, Imelda (2001). Fifth Province re-versings: the social construction of women lone parents' inequality and poverty. Journal of Family Therapy, 23: 253 - 277. https://doi.org/10.1111/1467-6427.00183

McCarthy, Imelda (2021). Re-Membering and Naturing my Life and Work in a Fifth Province. Murmurations: Journal of Transformative Systemic Practice, 4(1), 74-86. https://doi.org/10.28963/4.1.6

Palmer, Hugh (2021). Where did the Eco go in systemic practice? Murmurations: Journal of Transformative Systemic Practice, 4(1), 1-12. https://doi.org/10.28963/4.1.2

Raworth, Kate (2018). Doughnut Economics: Seven Ways to Think Like a 21st-Century Economist. London: Random House.

Rockström, Johan; Steffen, Will, Noone, Kevin et al. (2009). A safe operating space for humanity. Nature, 461, 472-475. https://doi.org/10.1038/461472a

Simon, Gail. (2021). Panmorphic Crisis: Cultural Rupture and Systemic Change. Murmurations: Journal of Transformative Systemic Practice, 4(1), 87-101. https://doi.org/10.28963/4.1.7

Watts, Nick et al. (2021). The 2020 Report of The Lancet Countdown on health and climate change: responding 
to converging crises. The Lancet, 397(10269), 129-170. https://doi.org/10.1016/S0140-6736(20)32290-X

Wallace-Wells, David (2019). The Uninhabitable Earth: A Story of the Future. Allen Lane.

\section{Author}

Philip Kearney completed his masters in family therapy at the graduate school of Hahnemann Medical College in Philadelphia in 1980. He was a co-founder of the Clanwilliam Institute in Dublin where he was Director of Training from 1988 to 2006. Currently, he is chair of An Taisce - the National Trust for Ireland.

E-mail: phil.kearney@muckduff.net

\section{Citation}

Kearney, Philip (2021). The EcoSystemic Return: clinical and political implications. Murmurations: Journal of Transformative Systemic Practice, 4(1), 102-118. https://doi.org/10.28963/4.1.8 